\title{
La figure du passeur dans l'histoire de la diffusion transnationale de la théorie des Cultural
}

\section{Studies (années 1990)}

\section{Diana COOPER-RICHET}

L'histoire des déplacements culturels, du voyage des idées et des pratiques, de la circulation des concepts et des théories, à travers les frontières officielles ou virtuelles qui séparent les pays, ou les aires culturelles, demeure encore largement à écrire, en dépit de l'engouement des chercheurs pour cette nouvelle approche historiographique. ${ }^{1}$ Il faut, à cet égard, rappeler que les aires culturelles ne sont pas des champs clos, ni des entités pures mais, au contraire, des lieux d'hybridation au sein desquels se construisent les identités nationales. Celles-ci sont le résultat de multiples apports extérieurs, d'imbrications multiples, d'échanges permanents et riches. ${ }^{2}$ L'histoire des sciences humaines n'échappe pas à ce phénomène de transferts culturels. Les contours de ce concept nouveau ont été dessinés par deux historiens français, Michel Espagne et Michael Werner ${ }^{3}$. Il s'agit, pour le premier d'entre eux, « d'une orientation méthodologique de la recherche en histoire visant à mettre en évidence les imbrications et les métissages entre les espaces nationaux et plus généralement les espaces culturels, une tentative pour comprendre par quels mécanismes les formes identitaires peuvent se nourrir d'importations » (ESPAGNE, 2005).

Ce «concept» permet d'envisager l'histoire dans une dimension transnationale ou transculturelle, c'est-à-dire d'analyser le passage d'un contexte culturel et intellectuel, national ou non, vers un autre, et d'y repérer les échanges. La notion de transfert culturel permet de mesurer les influences réciproques, d'analyser le rayonnement d'une pensée, de suivre le chemin parcouru par une idée, un savoir, une connaissance, une pratique, d'aller de manière dynamique au-delà du comparatisme, étant entendu que tout n'est pas comparable. Cette notion est particulièrement bien adaptée à l'étude de l'histoire des sciences humaines, notamment en association avec celle de passeur ou de médiateur culturel - en anglais on parle de cultural go-between -, qui lui est intimement liée (COOPER-RICHET, 2005, p. 13-17). Bien que cette notion de passeur culturel soit considérée, par certains chercheurs, comme n'étant que "d'une médiocre efficacité heuristique » (LOUÉ, 2004, p. 195), en l'absence d'autres plus opératoires elle demeure, pour beaucoup d'historiens, en dépit de son flou, de ses insuffisances, utile, voire indispensable, pour suivre et

\footnotetext{
* Centre d'Histoire Culturelle des Sociétés Contemporaines, Université de Versailles Saint-Quentin-en-Yvelines.
} 
expliquer les mécanismes de transferts culturels. Notons, enfin, que ces deux concepts ne sont pas propres au champ historique, ils font appel et peuvent être utilisés par différentes disciplines des humanités et des sciences sociales, comme la philosophie, la sociologie ou encore les études littéraires.

L'importance du rôle des passeurs de culture, dans la mise en circulation transnationale des idées, a depuis quelques années été mise en évidence dans un certain nombre de travaux, notamment en ce qui concerne le monde de l'édition et des médias en Europe au XIX ${ }^{\circ}$ et au $\mathrm{XX}^{\circ}$ siècle. ${ }^{4}$ Des historiens, comme Christophe Charle, ont souligné la façon par laquelle un enchaînement de causalités, parmi lesquelles des individus, peuvent contribuer au déplacement des connaissances. L'exemple de la diffusion des thèses, élaborées en Angleterre dans les années soixante, dites des Cultural Studies, et les circonstances dans lesquelles, un intellectuel d'origine belge, bien connu en Amérique Latine, plus particulièrement au Chili, Armand Mattelart, a été amené à jouer un rôle de passeur culturel, est particulièrement éclairant.

Armand Mattelart, universitaire au profil et à la carrière atypiques - à la fois international et hétérodoxe -, est un homme de culture double (CHARLE, 1992, p. 62-75), voire multiple, ce qui contribue largement à expliquer le rôle qu'il a joué dans la germination des Cultural studies à travers le monde.

\section{Armand Mattelart, passeur de culture.}

\section{Un homme multiple.}

Selon Christophe Charle, «l'homme double » est celui qui se trouve au carrefour de deux cultures émanant d'aires géographiques ou de strates sociales (populaire ou savante, rurale ou urbaine....) différentes, qui est donc en situation de jouer le rôle d'intermédiaire entre ces sphères en contribuant au commerce culturel, notamment entre les nations ${ }^{5}$. Armand Mattelart est, sans aucun doute, un homme double, voir un homme aux multiples facettes, dont le champ des transferts auxquels il contribue, s'étend bien au-delà de simples échanges bilatéraux.

Né en Belgique, à Jodoigne (Wallonie) en 1936, en terre francophone mais non française et qui cultive sa différence, Armand Mattelart considère que sa fibre cosmopolite vient en partie de la « géolocalisation » du petit pays dans lequel il a vu le jour et dans lequel cohabitent trois groupes linguistiques et culturels très différents : les Wallons, les Flamands et les Germanophones dans l'Est. La nation belge est de création relativement récente (1831) au regard de l'histoire européenne, et comme le prouvent de récents événements, elle repose sur un équilibre extrêmement fragile, que des phénomènes comme la désindustrialisation, et les difficultés économiques qu'elle entraîne, 
peuvent remettre en cause durablement. Le contexte de ces origines a sans aucun doute une part non négligeable dans l'ouverture d'esprit future d'Armand Mattelart.

Après la Secondaire Guerre mondiale, il fréquente un collège catholique ${ }^{6}$ - sa mère est pratiquante - qui organise chaque année des expositions sur les ordres religieux missionnaires qui œuvrent dans différentes régions du monde - du Sahara au Grand Nord canadien, en passant par les terres amazoniennes, mais aussi des conférences sur des hommes comme Raoul Follereau ${ }^{7}$ ou Albert Schweitzer ${ }^{8}$. Il s'engage à l'adolescence dans le mouvement scout, ce qui lui donna, pense-til, le goût de l'aventure. Jeune homme, il se lance dans de longs voyages solitaires, séjourne dans un kibboutz, puis dans un monastère au Liban (MATTELART, 2011, p. 137). Il interrompt ses études pendant deux ans pour rejoindre une petite communauté fraternelle, de quatre ou cinq personnes, se réclamant de Charles de Foucauld ${ }^{9}$. Dans ce cadre, il se consacre, dans un premier temps, aux ouvriers mineurs, notamment italiens, d'un bassin houiller de Wallonie, puis en Bretagne aux pécheurs et aux ouvriers agricoles.

Plus que double, Armand Mattelart, de par ces différentes expériences s'ouvre très tôt aux cultures étrangères, mais aussi à celles, diverses, du monde ouvrier, pour devenir, en quelque sorte, un passeur à vocation universelle.

\section{Une carrière internationale et hétérodoxe.}

La carrière professionnelle de l'universitaire Armand Mattelart est singulière parce qu'internationale et hétérodoxe. Internationale elle l'est, dès le départ. En effet, en 1962, à 1'âge de 26 ans, par le biais d'un prêtre jésuite de Louvain, il décide d'aller enseigner à l'Université catholique de Santiago du Chili, pays dans lequel il restera pendant 11 ans, jusqu'à son expulsion par le régime du général Pinochet, en 1973. Pendant trois ans, de 1970 à 1973, il travaille avec Salvador Allende sur les questions relatives à la communication de masse. Son intérêt pour l'Amérique Latine ne se démentira pas, puisqu'il collaborera régulièrement par la suite avec les grandes institutions académiques argentines, brésiliennes et mexicaines. Au début des années 1980, qui furent difficiles pour lui sur le plan professionnel, il travaille pour les Nations Unies, avant de se faire élire professeur de Sciences de l'Information et de la Communication, en France, à l'Université de Rennes II, puis, à la fin des années 1990, à Paris VIII. ${ }^{10}$

Ce parcours qui conduit Mattelart de Belgique en France, en passant par le Chili d'Eduardo Frey, d'Allende et de Pinochet, puis les Etats-Unis, sans oublier les nombreuses missions à l'étranger qui jalonnent cette carrière, est marqué du sceau de l'ouverture sur le monde, elle l'est également par le biais des sujets abordés, notamment ceux liés aux problèmes de la communication 
dans les sociétés modernes. Un profil de cette nature est, à cette époque, tout à fait hétérodoxe au sein de l'université française.

Cette hétérodoxie tient sans doute autant au caractère cosmopolite de l'homme, qu'à ses centres d'intérêts : l'information et la communication, un champ mal reconnu, voire marginalisé, pire encore méprisé, jusqu'à une période récente, par les disciplines historiques des sciences sociales et des humanités que sont l'histoire ou la sociologie, et qui se cherchait encore, il y a peu, une véritable identité. Dans un article, devenu par la suite, un ouvrage, écrit en collaboration avec Erik Neveu, professeur de science politique, d'abord formé à la sociologie, spécialiste de la pop music, puis du roman d'espionnage, les deux hommes se définissent comme des "provinciaux » (MATTELART; NEVEU, 2003, p. 14), c'est-à-dire dans le monde universitaire français, des enseignants-chercheurs qui ne sont pas rattachés à l'une des grandes universités parisiennes et dont la légitimité symbolique est moins grande que celle de leurs collègues, de la «Sorbonne » ${ }^{11}$ par exemple. Ce sont des universitaires dont la carrière est loin d'avoir été rectiligne, passant d'une discipline à une autre, d'un sujet non légitime à un autre qui ne l'est pas plus.

C'est sans doute cette position atypique dans le monde académique qui a conduit Armand Mattelart à être l'un des pionniers de l'introduction et de la diffusion, en France, des Cultural Studies britanniques. C'est ce rôle de médiateur, de passeur culturel, qui va être abordé dans les pages qui suivent.

\section{La diffusion des Cultural studies.}

\section{Les Cultural Studies.}

Dans les années 1950-1960-1970, les Cultural Studies britanniques vont offrir un espace, nouveau et fécond, de dialogue entre les sciences sociales. Elles sont le résultat de la réflexion et des recherches d'un petit groupe d'intellectuels, situés politiquement à gauche, parfois militant, institutionnellement marginaux et originaires, pour la plupart d'entre eux, de milieux sociaux peu favorisés, ouvriers plus particulièrement. Tel est le cas, du plus connu d'entre eux, le professeur de littérature Richard Hoggart, auteur du célèbre Uses of literacy. Aspects of British working class life (1957), publié en France sous le titre La culture du pauvre. Etude sur le style de vie des classes populaires en Angleterre (1976). ${ }^{12}$ Aux côtés de 1'historien E.P. Thompson (The Making of the British working class, 1963) et de Raymond Williams, spécialiste de sociologie de la culture (Culture and Society, 1958), voire encore de Stuart Hall ${ }^{13}$, ils commencent à travailler, dans des universités peu prestigieuses et dans des départements de formation tout au long de la vie éducation pour adultes - notamment, sur des objets considérés, jusqu'à là, comme non légitimes et 
à publier dans des revues engagées à gauche, telles que New Left Review, Past and Present ou History Workshop.

Ils fondent, en 1964 à Birmingham, le Centre of Contemporary Cultural Studies dans lequel ils développent librement leur nouvelle approche. En quoi consiste-t-elle? Il s'agit d'étudier les phénomènes culturels, parce que selon ces chercheurs, c'est dans le domaine de la culture que la tension entre domination et résistance est la plus forte. Ils se lancent donc dans une bataille contre les médias de masse accusés d'abaisser le niveau culturel des classes populaires et de les éloigner de la culture spécifique qui est la leur, pour ensuite l'étudier en tant que phénomène culturel propre. Ils recommandent donc de ne plus enseigner seulement les œuvres reconnues comme appartenant au canon littéraire, mais de se pencher sur la littérature populaire, écrite ou orale, la chanson, le sport, d'étudier les médias, mais aussi la publicité et ses méfaits.

Les recherches menées sur des objets de cette nature sont tout à fait pionnières à cette époque d'autant qu'elles associent, dans leur réflexion, différentes disciplines, telles que la littérature, la sociologie, l'histoire, mais aussi et ceci est tout à fait nouveau, l'étude sociologique et critique des médias et des moyens de communication de masse. Elles ne connaitront donc pas, immédiatement, ni en Grande-Bretagne, ni de l'autre côté de la Manche, un très grand retentissement. Leur germination se fera lentement et tardivement, plus particulièrement en France.

\section{Germination des Cultural Studies.}

Mis à part, la publication par les Editions de Minuit, en 1976 - soit près de 20 ans après sa parution en Angleterre - grâce à la contribution de Pierre Bourdieu ${ }^{14}$ et de Jean-Claude Passeron ${ }^{15}$, du livre magistral de Richard Hoggart, les Cultural Studies demeurent à peu près inconnus des intellectuels français qui, pour la plupart, à gauche en tout cas, sont immergés dans le Structuralisme. Il faut attendre 1984 et la publication dans la revue Réseaux de l'article fondateur de Mattelart et Neveu. Pour la première fois, dans un long texte de 40 pages, les origines, le développement et les enjeux de cette réflexion de leurs collègues britanniques sur la culture et son rôle dans la société sont longuement analysés et présentés aux intellectuels français.

Ce sont donc deux universitaires difficilement classables, mais qui tous deux s'intéressent aux médias et à la communication au sein des sociétés occidentales ${ }^{16}$, qui les premiers, bien que tardivement - 30 ans après les débuts de cette réflexion novatrice et stimulante sur la culture - s'en font les passeurs internationaux, après avoir fait le constat d'une carence, en France, dans ce domaine. La réception sur le Continent a été relativement limitée. Néanmoins, comme le montrent les deux auteurs, les Cultural Studies ont, quant à elles, empruntées des éléments à ce que l'on appelle la French Theory - c'est-à-dire les thèses de Louis Althusser, celles de Jacques Lacan, de 
Claude Lévy-Strauss, de Roland Barthes, de Julia Kristeva et de Michel de Certeau - voire aussi aux écoles de Chicago et de Francfort et à la tradition marxiste, notamment à Gramsci. L'hybridation, c'est-à-dire les transferts culturels, dans le processus desquels Armand Mattelart joue le rôle de passeur, ont donc été plus riches dans le sens France-Angleterre, que dans l'autre, le champ intellectuel français étant, pour des raisons historiques et linguistiques - les intellectuels français manient mal les langues étrangères, y compris l'anglais -, moins ouvert que d'autres, comme celui de l'Amérique Latine notamment. En France, c'est l'histoire culturelle qui s'est développée, dérivée de «l'histoire des mentalités », telle qu'elle a été imaginée par Lucien Febvre (1878-1956) et Marc Bloch (1886-1944) au sein de l'Ecole des Annales et non les Cultural studies, une approche interdisciplinaire.

Armand Mattelart a, comme de nombreux travaux l'ont montré, joué un rôle non négligeable dans l'introduction des sciences sociales en Amérique Latine, plus particulièrement au Chili. Il a, également, analysé les interactions entre les Cultural Studies (MATTELART; NEVEU, 2003, p. 7781) et le continent sud-américain, une région du monde dans laquelle le questionnement sur les processus culturels, notamment en ce qui concerne les cultures populaires ${ }^{17}$, est, depuis longtemps, au centre des préoccupations des intellectuels argentins, brésiliens, péruviens, voire colombiens en quête d'une identité propre à leurs pays et à leurs cultures, compte tenu de la proximité des EtatsUnis et de ses productions culturelles de masse. Armand Mattelart montre que cette réflexion - celle des estudios culturales, qui regroupent des recherches d'une grande variété et d'une grande originalité - a, presque toujours été conduite pendant les périodes de dictature ou juste après, dans un climat politique qui ne s'y prêtait guère. C'est pourtant dans ces conditions que Hoggart et Williams ont été lus en Argentine (MATTELART; NEVEU, 2003, p. 78) aux Etats-Unis et en Australie, et que les études sur la réception, voire l'anthropologie urbaine se sont développées ((MATTELART; NEVEU, 2003, p. 79). Le contexte est donc très différent et beaucoup moins favorable que celui dans lequel, les Cultural Studies britanniques ont vu le jour dans les années 1960.

\section{Conclusion}

La circulation des idées est rendue possible par l'intervention de multiples intermédiaires, aussi différents que les imprimés, plus particulièrement les revues, les groupes, par exemple les partis politiques ou les communautés religieuses, mais aussi, bien évidemment, les individus qui, de par leurs origines familiales, culturelles, géographiques, leur formation, leur parcours professionnel, sont ouverts sur le monde et sa diversité. Ainsi placés, au carrefour de plusieurs cultures, ils sont en capacité de mettre en relation, consciemment ou inconsciemment, «Les quatre parties du 
monde $»^{18}$, contribuant par là-même à la mondialisation de la pensée, un mouvement entamé il y a plusieurs siècles déjà - au $\mathrm{XVI}^{\circ}$ et $\mathrm{XVII}^{\circ}$ - comme l'a montré, dans de nombreux travaux, l'historien Serge Gruzinski, plus particulièrement en ce qui concerne les liens entre l'Amérique Latine et l'Europe, mais aussi avec l'Asie, voire l'Afrique.

Dans le présent exemple, différents facteurs, médiateurs ou éléments de médiation ont, ensemble, contribués à la mise en circulation de courants de pensée propres aux sciences humaines et sociales ou de manières d'envisager les humanités. Au centre il y a, en premier lieu, un individu, Armand Mattelart, mais aussi des communautés religieuses ouvertes sur le monde et sur la société qui ont joué un rôle, sans doute essentiel, dans sa formation et dans la transmission de leurs valeurs. Il y a également une revue, Réseaux, utilisée par Mattelart et Neveu pour faire connaître, en France et ailleurs, les Cultural Studies britanniques, près de trois décennies après leur développement de l'autre côté de La Manche, contribuant ainsi à faire évoluer les modes de penser et à faire se confronter plus largement les idées.

\section{Références bibliografiques}

ABREU, Marcia; et MOLLIER Jean-Yves. La Circulation des imprimés et mondialisation de la culture au XIX ${ }^{\circ}$ siècle, avec les universités de Versailles Saint-Quentin-en-Yvelines, de Campinas, de São Paulo et Fédérale du Minas Gerais au Brésil.

BOUREL, Dominique; MOTZKIN, Gabriel. Les Voyages de l'intelligence. Passages des idées et des hommes: Europe, Palestine, Israël. Paris: CNRS-Editions, 2002.

CHARLE, Christophe. Le temps des hommes doubles. Revue d'histoire moderne et contemporaine, n. 39, janvier-mars 1992, p. 62-75.

COOPER-RICHET, Diana. Introduction. Passeurs culturels dans le mondes des médias et de l'édition en Europe (XIX ${ }^{\circ}$ et $\mathbf{X X}^{\circ}$ siècles). Diana Cooper-Richet, Jean-Yves Mollier, Ahmed Silem dir. Lyon: Presses de l'ENSSIB, 2005.

ESPAGNE, Michel. Transferts culturels et histoire du livre, communication au colloque francochinois. Chine-Europe: histoires de livres, Bibliothèque Nationale de Chine, Pékin, 15-16 octobre 2005.

GRUZINSKI, Serge. Les Quatre parties monde. Histoire d'une mondialisation. Paris: Editions de La Martinière, 2004.

HALL, Stuart. Identités et cultures. Politiques des Cultural studies. Paris: Editions Amsterdam, 2007.

LOUÉ, Thomas, Les passeurs culturels au risque des revues (France, $\mathrm{XIX}^{\circ}$ et $\mathrm{XX}^{\circ}$ siècles). In: Passeurs culturels dans le mondes des médias et de l'édition en Europe (XIX ${ }^{\circ}$ et $\mathrm{XX}^{\circ}$ siècles). Diana Cooper-Richet, Jean-Yves Mollier, Ahmed Silem (dir). Lyon: Presses de l’ENSSIB, 2005. 
MATTELART, Armand; NEVEU, Erik. Introduction aux Cultural Studies. Paris: La Découverte, coll. Repères, 2003.

MATTELART, Armand. Mission Santiago. El mundo académica jesuita y los inicios de la cooperación internacional católica. Santiago: LOM ediciones, 2011.

PASSERON, Jean-Claude. Littérature et sociologie: retour sur Richard Hoggart. L'Art de la recherche, P.M. Menger et Jean-Claude Passeron éd. Paris: La Documentation française, 1994

\section{Notes}

${ }^{1}$ Voir BOUREL, Dominique; MOTZKIN, Gabriel. Les Voyages de l'intelligence. Passages des idées et des hommes: Europe, Palestine, Israël. Paris: CNRS-Editions, 2002, mais également le programme de recherche que dirigent ABREU, Marcia; et MOLLIER Jean-Yves. La Circulation des imprimés et mondialisation de la culture au XIX $X^{\circ}$ siècle, avec les universités de Versailles Saint-Quentin-en-Yvelines, de Campinas, de São Paulo et Fédérale du Minas Gerais au Brésil.

${ }^{2}$ Voir les travaux de GRUZINSKI, Serge. Les Quatre parties monde. Histoire d'une mondialisation. Paris: Editions de La Martinière, 2004.

${ }^{3}$ Voir le numéro spécial de la Revue Germanique Internationale, « L'horizon anthropologique des transferts culturels », $\mathrm{n}^{\circ}$ 21, janvier 2004. Michel Espagne, Les transferts culturels franco-allemands, Paris, PUF, 1999. Transferts culturels France-Allemagne-Russie, Ekaterina Dmitrieva et al. éd., Paris, Editions de la Maison des Sciences de l'Homme, 1996.

${ }^{4}$ Voir COOPER-RICHET, Diana. Introduction. In: Passeurs culturels dans le mondes des médias et de l'édition en Europe (XIX $X^{\circ}$ et $X X^{\circ}$ siècles), p. 13-17.

${ }^{5}$ Le commerce culturel des nations, France-Allemagne, XVIII ${ }^{\circ}-X I X^{\circ}$ siècles, Revue de Synthèse, janvier-juin $1992, \mathrm{t}$. CXIII, $n^{\circ} 1-2$.

6 «De Jodoigne a Santiago: La experiencia latinoamericana de Armand Mattelart», Mission Santiago. El mundo académica jesuita y los inicios de la cooperación internacional católica, Santiago, LOM ediciones, 2011, p. 87-99.

${ }^{7}$ Raoul Follereau (1903-1977), militant chrétien, à l'origine d'une Fondation qui porte son nom dédiée à la lutte contre la lèpre, plus particulièrement dans les pays d'Afrique.

8 Albert Schweitzer (1875-1965), médecin et pasteur protestant, est surtout connu pour l'hôpital qu'il fonda à Lambaréné au Gabon, afin d'y soigner et de faire des recherches sur les pathologies locales.

${ }^{9}$ Charles de Foucauld (1858-1916), explorateur et missionnaire français qui vécut en ermite au Sahara. Il est l'auteur de travaux sur les Touaregs. Béatifié en 2005, il est à l'origine d'une véritable famille religieuse et d'associations spirituelles et d'amitié fraternelle, comme celle à laquelle appartiendra Armand Mattelart.

${ }^{10}$ Entretien avec Armand Mattelart, à Paris, le 7 octobre 2008.

${ }^{11}$ Rappelons que depuis la réforme des universités françaises, qui suivit le mouvement social de 1968, la Sorbonne n'existe plus. Les étrangers continuent de parler de cette institution historique. Certaines universités parisiennes accolent cette étiquette prestigieuse à leur nom, comme par exemple Paris III-Sorbonne Nouvelle.

${ }^{12}$ Paris, Editions de Minuit. Cet ouvrage a été traduit en France à l'initiative des sociologues Pierre Bourdieu et JeanClaude Passeron. Dans les années 1970 leur laboratoire de recherche s'intéresse, comme leurs collègues britanniques des Cultural studies, à des objets peu légitimés tels que la culture populaire, la littérature jeunesse, la photographie ou encore les caricatures.

${ }^{13}$ HALL, Stuart. Identités et cultures. Politiques des Cultural studies. Paris: Editions Amsterdam, 2007.

${ }^{14}$ Les travaux de Pierre Bourdieu sur la culture commencent avec un article dans la revue Les Temps modernes, vol. 22 , n²46, 1966, p. 865-906 : "Champ intellectuel et projet créateur », ils se poursuivent dans L'Année sociologique, avec «Marché des biens symboliques », XXII, 1971, p. 49-126 et se concrétisent dans la publication de l'ouvrage Les Règles de l'art. Genèse et structure du champ littéraire, Paris, Seuil, 1992.

${ }^{15}$ PASSERON, Jean-Claude, «Littérature et sociologie: retour sur Richard Hoggart », L'Art de la recherche, P.M. Menger et Jean-Claude Passeron éd. Paris: La Documentation française, 1994.

${ }^{16}$ Il est, notamment, l'auteur avec Michèle Mattelart de Penser les médias, Paris, La Découverte, 1886.

${ }^{17}$ MATTELART, Armand; NEVEU, Erik. Introduction aux Cultural Studies, Mattelart prend notamment l'exemple des telenovelas, p. 78 et 79.

${ }^{18}$ Voir le titre de l'ouvrage de Serge Gruzinski, Les quatre parties du monde. Histoire d'une mondialisation.

Recebido em abri1/2013.

Aprovado em junho/2013. 